\title{
OS DESAFIOS PARA EFETIVAÇÃO DA POLÍTICA NACIONAL DE RESÍDUOS SÓLIDOS FRENTE A FIGURA DO CONSUMIDOR- GERADOR
}

Márcio de Souza Bernardes ${ }^{1}$

\begin{abstract}
RESUMO
Em termos de defesa de um meio ambiente ecologicamente equilibrado a questão dos resíduos sólidos desponta com um dos principais desafios. No Brasil, a recente Lei $\mathrm{n}^{\circ}$. 12.305, de 2 de agosto de 2010, institui a Política Nacional de Resíduos Sólidos, propondo uma série de mecanismos destinados à gestão integrada e ao gerenciamento ambientalmente adequado dos resíduos sólidos, inaugurando a chamada responsabilidade compartilhada pelo ciclo de vida dos produtos, entre setores públicos, inciativa privada e consumidores. De forma a incentivar ao cumprimento das obrigações da coletividade na implantação dessas politicas, a referida lei explicita o princípio do protetor-recebedor, especialmente no que se refere aos instrumentos econômicos para o atingimento de seus objetivos. Em face disso, o presente artigo tem por objetivo propor uma reflexão sobre o tímido avanço na questão dos resíduos sólidos frente à formatação da sociedade moderna do consumo, e a posição do consumidor-gerador, imerso em uma ética da descartabilidade e sem estímulos objetivos para participar do compartilhamento da responsabilidade proposta. Para a realização do presente texto foi utilizado o método hipotético-dedutivo, partindo-se da hipótese da dificuldade de efetivação da lei, especialmente a partir de premissas históricas, culturais e legais para a verificação da situação da efetividade da Política Nacional do Meio Ambiente.
\end{abstract}

Palavras Chaves: Resíduos Sólidos. Responsabilidade Compartilhada. Consumidor-gerador

\section{INTRODUÇÃO}

A sanção da Lei $n^{\circ}$ 12.305, em 02 de agosto de 2010, após vinte e um anos de tramitação no congresso nacional, foi comemorada por uma parcela significativa da mídia e da própria sociedade como um grande avanço na defesa do meio ambiente, no que se refere ao tratamento dos resíduos sólidos. Sem dúvidas, a Lei da Política Nacional dos Resíduos Sólidos apresenta instrumentos louváveis como a gestão integrada, a Responsabilidade Compartilhada pelo Ciclo de Vida dos Produtos, entre entes governamentais, iniciativa privada (produtores) e consumidores; o incentivo de medidas ambientalmente sustentáveis, através da aplicação do Princípio do ProtetorRecebedor e do Poluidor-Pagador; a ratificação de uma Educação Ambiental voltada para o chamado "consumo sustentável", dentre outros de igual relevância.

Em que pese tudo isso demonstrar um inegável avanço quanto ao tema resíduos, uma análise um pouco mais ampla da lei e da realidade social, anunciam dificuldades

\footnotetext{
${ }^{1}$ Mestre em Direitos Sociais e Políticas Públicas pela Universidade de Santa Cruz do Sul (UNISC), Especialista em Direito Processual Civil pela Universidade Luterana do Brasil (ULBRA). Graduado Direito pela Universidade Federal de Santa Maria (UFSM). Professor do Curso de Direito do Centro Universitário Franciscano (UNIFRA). Advogado. E-mail: msbernardes@ hotmail.com
} 
consideráveis para a sua efetivação, especialmente porque o lixo encontra-se enraizado no habitus contemporâneo, fazendo parte da própria estrutura da sociedade capitalista.

Nesta perspectiva, o presente texto busca apresentar algumas reflexões sobre alguns instrumentos trazidos pela Política Nacional de Resíduos Sólidos, e a sua possível ineficácia em face de outros fatores que parecem andar na contramão daquilo que se busca solucionar. Utilizando o método hipotético-dedutivo, em um primeiro momento serão abordados alguns conceitos e aspectos do lixo e dos resíduos sólidos trazidos pela Lei 12.303/2010. Após serão analisados alguns instrumentos para a efetivação da lei, especialmente os institutos da responsabilidade compartilhada pelo ciclo de vida dos produtos e seus instrumentos de incentivo, como os princípios do poluidor-pagador e do protetor-recebedor, para, por fim, analisar a situação do consumidor-gerador na sociedade contemporânea do consumo, apontando para os imensos obstáculos para solução do problema nos moldes da lei, em que pese seu avanço.

\section{LIXO, RESÍDUOS SÓLIDOS E REJEITO NA LEI 12.305/2010.}

Os resíduos da atividade humana, ou lixo $^{2}$, no sentido já esteriopipado pela sociedade ocidental, muito embora tenham destacada relevância na segunda metade do último século, tornando-se um problema a ser enfrentado pela coletividade e de interesse do poder público, estão presentes desde sempre nos assentamentos humanos. Nos dizeres de Patrícia Lemos (2011, p. 81), fazem parte da história do ser humano na terra, o que se pode verificar nos registros arqueológicos, onde é possível identificar uma série de objetos rejeitados e que foram decorrentes da atividade econômica. Isso porque, como afirma Maurício Waldman (2010, p. 44) atuar no mundo e gerar resíduos são atitudes mutuamente consorciadas.

\footnotetext{
${ }^{2}$ De acordo com Maurício Waldman, muito embora tenamos que repensar a utilização dos termos lixo $e$ resíduos (o que faz com muita propriedade a Lei $\mathrm{n}^{\circ}$ 12305/2010), o lixo é uma palavra enraizada em nossas sociedades. Do ponto de vista semântico, podemos certificar que o lixo seria todo o material inútil, todo material descartado posto em lugar público, tudo aquilo que "se joga fora", "não presta", condição à qual são evocadas longas catilinárias devotadas à sua nocividade, periculosidade, intratabilidade, etc. Uma outra conceituação bastante difusa qualifica o lixo como sendo as "sobras" no processo produtivo, particularmente de origem fabril”. (p. 18).
} 
III SEMINÁRID ECDLOGIA

A produção de resíduos, portanto, é inerente a estarmos vivos, e, ato-contínuo, ao fato de consumirmos. O consumo e a geração de resíduos estão mutuamente ligados. Decorrente do consumo, e da produção de itens a serem consumidos, tudo o quanto não serve mais, não tem utilidade, não poderá suprir necessidades huamanas, é descartado, desconsiderado, colocado à margem. O consumo, em si, etimologicamente, vem de consumire, que significa, de acordo com Lemos (2011, p.23) gastar, utilizar, despender, extinguir, destruir. O que sobra deste ato é considerado lixo, rejeito, resíduo, não presta.

A partir desta perspectiva, pode-se verificar toda a carga pejorativa que se atribuiu a palavra lixo ao longo da história, de modo a considerá-lo sempre com algo fora do sistema. Em outras palavras, como afirma Maurício Wladman (2010), sempre houve a tendência em abstrair os fenômenos da vida humana de sua contextualização geográfica, histórica, cultural e social, o que se nota especiamente, nos discursos que versam sobre o lixo. $\mathrm{O}$ mesmo autor afirma que

\begin{abstract}
a noção de lixo no mundo ocidental está energizada por uma trama simbólica regurgitante de valores pejorativos, advogando à condição de resíduo, a mais abjeta incompatibilidade com a convivência social. Consignada no plano lingüístico, suas derivações podem ser conferidas numa rápida consulta aos dicionários. Senão vejamos: lixo - o que se varre da casa, do jardim, da rua, e se joga fora: entulho; tudo o que não presta e se joga fora; Sujidade, sujeira, imundície; Coisa ou coisas inúteis, velhas, sem valor; ralé (WALDMAN, 2010, p. 22-23)
\end{abstract}

Contudo, a partir do momento em que o lixo, a sobra da produção e do consumo passa a ser considerado como um problema ambiental, portanto difuso, o que ocorre de forma mais nítida a menos de um século, com os fenômenos da produção e consumo em massa $^{3}$, nota-se um movimento no sentido de modificar a carga pejorativa que recai sobre o lixo, resignificando a carga dada a esta palavra. Ainda de acordo com Maurício Waldman (2010, p.27), se verifica claramente a discussão que se trava desde as décadas finais do século passado postulando os resíduos - ou melhor ainda os resíduos sólidos - enquanto eixo de um releitura conceitual do que tradiconalmente é definido

\footnotetext{
${ }^{3}$ Importante mencionar que a preocupação ambiental no que se refere ao lixo é recente em termos de políticas públicas, não de problemas já evidenciados. Em outros tempos já se verificou os problemas causados pelo lixo. Lemos (2011, p. 83), dá conta que na Idade Média com o desenvolvimento do comércio e com o crescimento das cidades, os problemas relacionados aos resíduos foram dramáticos. Os resíduos eram, comumente, lançados nas ruas. Este fato é apontado como a causa da peste negra na Europa Ocidental, resultando na morte de metade da população em apenas quatro anos.
} 
como lixo. Estas discussões, por óbvio, foram fundamentais para o legislador brasileiro que, após vinte e um anos de discussões, busca remodelar a palavra lixo, a partir da Lei de Política Nacional de Resíduos Sólidos (PNRS), de agosto de $2010^{4}$.

Assim, para a Lei no 12.305/2010, o lixo seria gênero, do qual seriam espécies os resíduos sólidos e os rejeitos. No art. $3^{\circ}$, XVI, tem-se o conceito legal de resíduo sólido, nos seguintes termos:

\begin{abstract}
material ou substancia, objeto ou bem descartado resultante de atividades humanas em sociedade, cuja destinação final se procede, se propõe proceder ou se está obrigado a proceder nos estados sólido ou semissólido, bem como gases contidos em reipientes e líquidos cujas particularidades tornem inviável o seu lançamento da rede pública de esgotos ou em corpos d'água, ou exigam para isso soluções técnicas ou economicamente inviáveis em face da melhor tecnologia disponível. (LEI n ${ }^{\circ} 12.305$ de 02 de agosto de 2010, art. $3^{\circ}$, XVI)
\end{abstract}

$\mathrm{O}$ rejeito, conforme o art. $3^{\circ}, \mathrm{XV}$ seriam todos os resíduos sólidos que, depois de esgotadas todas as possibilidades de tratamento e recuperação por processos tecnológicos disponíveis e economicamente viáveis, não apresentem outra possibilidade que não a disposição final ambientalmente adequada.

Poderiamos referir, assim, que o lixo seria toda a sobra, o resto da atividade produtiva ou de consumo, considerado pela lei da PNRS como Resíduos, enquanto Resíduo Sólido, por sua vez, seria todo o Resíduo (lixo) que poderá ser reincorporado, de alguma forma, ao sitema produtivo ou de consumo, conforme se depreende dos incisos VII, XIV e VXIII, do art. $3^{\circ}$, quando definem, respectivamente, destinação final ambientalmente adequada, reciclagem e reutilização. Rejeito, de outro lado, seria todo o resíduo que não teria a posibilidade de reincorporação no sistema, de acordo com a leitura dos incisos VIII e XV do mesmo artigo $3^{\circ}$, versando sobre disposição final ambientalmente adequada, que incluiria a utilização de aterros.

A partir desta "nova" identificação do lixo, agora denominado Resíduo, Resíduo Sólido e Rejeito, a PNRS, que integra a Política Nacional do Meio Ambiente, Lei. $\mathrm{n}^{\circ}$ 6.938/81, busca incorporar no Brasil uma série de mecanismos para enfrentar o problema que se apresenta como um dos mais complexos e relevantes para o dirieto

\footnotetext{
${ }^{4}$ Diga-se, contudo, que a retirada da palavra lixo já vinha sendo adotada por outras normas nacionais, a saber, a Resolução 5/93 do CONAMA, a NBR n. 10.004/1987, da Associação Brasileira de Normas Técnicas - ABNT, e a própria Lei $\mathrm{n}^{\circ} 11.445 / 2007$, que em seu artigo $6^{\circ}$ considera o Resíduo Sólido como uma espécie de Lixo, ao dispor que "o lixo originário de atividades comerciais, industriais e de serviços cuja responsabilidade pelo manejo não seja atribuída ao gerador pode, por decisão do poder público, ser considerado resíduo sólido urbano".
} 
III SEMINÁRII ECDLOGIA

POLÍTICA

E DIREITO NA AMÉRICA LATINA

ambiental, especialmente em razão da crescente geração de tais resíduos que, anualmente, tem superado a taxa de crescimento populacional, significando um evidente aumento do consumo e da descartabilidade.

\title{
2 A GERAÇÃO DE RESÍDUOS NO BRASIL E OS MECANISMOS DA POLÍTICA NACIONAL DE RESÍDUOS SÓLIDOS
}

Nas últimas cinco décadas o Brasil passou por um profundo processo de mudanças estruturais, o que significou a entrada do país na chamada modernidade industrial. Dentre vários fatores de interesse, estão o crescimento populacional, a industrialização, a formação de metrópolis e conurbações, mudanças de hábitos de consumo e, por óbvio, a degradação ambiental no campo e na cidade decorrente destes fatores.

Dentro da perspectiva da degradação ambiental das cidades, um dos pontos mais relevantes tem sido a geração de resíduos sólidos urbanos, e, mais especificamente, os Resíduos Sólidos Domésticos (RDO). Em verdade, em todo mundo ocidental esta tem sido uma das maiores preocupações no que se refere aos problemas do Lixo. Maurício Waldman (2010) refere que os Resíduos Sólidos Domésticos apresentam-se como agentes de primeira ordem na construção do Mundo do lixo, constituindo-se como o nó górdio da questão dos resíduos. Alguns dados colhidos nos últimos anos demonstram a dimensão do probelma.

\begin{abstract}
A literatura especializada dá plena razão à angústia provocada pela escalada do lixo. No mundo, são descartados diariamente 2 milhões de toneladas de resíduos domiciliares, cifra que ao longo de um ano fornece o vultoso total de 730 milhões de toneladas. Outra planilhas revelam que a somatória dos refugos provenientes das atividades anualmente levadas a cabo pelos humanos resulta num monturo de 30 bilhões de toneladas. Continuando este ritmo frenético de geração de rejeitos, teremos em 2.050 uma montanha de 1,5 trilhão de toneladas de dejetos. (WALDMAN, 2010, p. 45)
\end{abstract}

No Brasil os dados também se mostram alarmantes. Anualmente a Associação Brasileira de Lipeza Pública e Resíduos Especiais - ABRELPE -, lança o Panorama dos Resíduos Sólidos no Brasil, através do qual dá conta do montante de resíduos produzidos anualmente no Brasil, incluindo a análise de produção per capita e as formas de descartabilidade. 
Uma análise dos relatórios ${ }^{5}$ dos anos de 2009, 2010 e 2011, demonstram que, anualmente, a produção de resíduos no Brasil tem ultrapassado a taxa de crescimento populacional, significando que há um consumo crescente e uma crescente descartabilidade no país. Entre os anos de 2008 e 2009, a geração de resíduos saltou de 52.9 milhões de Toneladas/ano para mais de 57 milhões. Um crescimento anual de 7,7\%. Entre 2009 e 2010, verificou-se um salto de 57 t/ano para 60.8 t/ano, um aumento de 6,8\%; entre 2010 e 2011, verificou-se um salto para 61.9 t/ano, um percentual de 1,8\%. Em que pese uma aparente redução nos percentuais de 2009 a 2011, em todos os anos verificou-se um aumento de geração de resíduos superior a taxa de crescimento populacional. Entre 2010 e 2011, segundo dados do IBGE, o crescimento populacional foi de $0,9 \%$. Significando que, mesmo no ano em que se constatou um percentual menor de evolução da geração de resíduos $(1,8 \%)$, sua taxa foi o dobro da taxa de crescimento populacional no país.

Vive-se, portanto, num Brasil arrebatado pela cultura do consumo, do descarte e do desperdício. Este é o cenário que tem afligido pesquisadores, gestores públicos e a população em geral, e que se busca minimamente organizar através da Lei de PNRS de 2010. Mas com que instrumentos?

Neste sentido, a Lei $n^{\circ}$ 12.305/2010 trouxe uma série de mecanismos jurídicos. Em primeiro, adota como princípios como a visão sistêmica na gestão dos resíduos, considerando o problema a partir de variáveis ambiental, social, cultural, econômica, tecnológica e de saúde pública ${ }^{6}$; e a cooperação entre as diferentes esferas do poder público, do setor empresarial e demais segmentos da sociedade.

$\mathrm{Na}$ linha dos princípios da visão sistêmica e da cooperação entre as diversas esferas envolvidas, de forma a enfrentar o problema da falta de responsabilização de todos envolvidos na produção de resíduos, a Lei da PNRS inaugura em esfera federal a chamada responsabilidade compartilhada pelo ciclo de vida do produto. Além disso, lança mão de outros instrumentos jurídicos para sua aplicabilidade, dando corpo aos princípios do poluidor-pagador, através de sanções aplicadas àqueles que destinarem de forma inadequada os resíduos, e do protetor-recebedor, através de instrumentos

\footnotetext{
${ }^{5}$ Panorama dos Resíduos Sólidos no Brasil, dos anos de 2009, 2010 e 2011, disponíveis, em <http://www.wtert.com.br/home2010/arquivo/noticias_eventos/Panorama2009.pdf >; <http://www.wtert.com.br/home2010/arquivo/noticias_eventos/Panorama2010.pdf $>$ e <http://www.wtert.com.br/home2011/arquivo/noticias_eventos/Panorama2011.pdf> ${ }^{6}$ Art. $6^{\circ}$ da Lei ${ }^{\circ} 12.305 / 2010$
} 
III SEMINÁRII ECDLDGIA

PDLÍTICA

E DIREITO NA AMÉRICA LATINA

econômicos ${ }^{7}$ indutores de da prevenção, precaução, redução de geração de resíduos, e tecnologias que visem ao desenvolvimento e consumo sustentáveis.

Dentre os diversos instrumentos, o presente texto propõe-se, sem a pretensão de esgotar o tema, analisar a Responsabilidade Compartilhada pelo Ciclo de Vida dos Produtos e os instrumentos indutores das práticas ambientalmente responsáveis pelos diversos setores da sociedade, especificamente aqueles decorrentes do princípio do recebedor-pagador, que se apresenta com destaque na lei e na sua regulamentação, através de incentivos fiscais, financeiros ou creditícios.

\section{A RESPONSABILIDADE COMPARTILHADA E OS PRINCÍPIOS DO POLUIDOR PAGADOR E DO PROTETOR RECEBEDOR COMO FORMA SUA EFETIVAÇÃO}

A PNRS institui a responsabilidade compartilhada pelo ciclo de vida dos produtos, e a toma como um de seus objetivos elencados no art. $6^{\circ}$, sendo um instrumento que busca dar concretude ao princípio da cooperação entre os diversos setores públicos e privados responsáveis pela produção de resíduos no país. Conforme se lê do art. $3^{\circ}$, nas definições adotadas pela lei

a responsabilidade compartilhada é um conjunto de atribuições individualizadas e encadeadas dos fabricantes, importadores, distribuidores e comerciantes, dos consumidores e dos titulares dos serviços públicos de limpeza urbana e de manejo dos resíduos sólidos, para minimizar o volume de resíduos sólidos e rejeitos gerados, bem como para reduzir os impactos causados à saúde humana e à qualidade ambiental decorrentes do ciclo de vida dos produtos. (Lei $\mathrm{n}^{\circ} 12.305 / 2010$, art. $3^{\circ}$, XVII)

Dentre os objetivos da responsabilidade compartilhada, presente no art. 30 da PNRS estão compatibilizar os interesses entre os agentes economicos e sociais e os processos de gestão empresarial e mercadológica com os de gestão ambiental (I); promover o aproveitamento de resíduos sólidos, direcionando-os para a sua cadeia produtiva (II); reduzir a geração de resíduos sólidos, o desperdício de materiais, a poluição e os danos ambientais; (III) incentivar a utilização de insumos de menor

${ }^{7}$ Art. 42 da Lei $\mathrm{n}^{\mathrm{o}}$ 12.305/2010 
agresividade ambiental (IV); estimular o desenvolvimento de mercado, a produção e o consumo de produtos derivados de materiais reciclados e recicláveis (V).

$\mathrm{Na}$ mesma seção destinada à responsabilidade compartilhada, pode-se verificar obrigações que recaem sobre fabricantes, importandores, distribuidores e comerciantes (art. 31), a obrigatoriedade de implementar logística reversa de determinados produtos (art. 33) e obrigações dos consumidores (art. 35) sempre que estabelecido um sistema de coleta seletiva pelo plano municipal.

Um análise inicial dos dispositivos legais, leva a crer que há uma maior preocupação nas figuras dos fabricantes, importadores, comerciantes e poder público, quanto a responsabilidade compartilhada, destinando-se apenas um dos artigos aos consumidores, e ainda assim, de forma vaga, detendo-se no descarte adequadamente condicionado dos resíduos sólidos gerados.

Além disso, parece a preocupaçao recair no estímulo do mercado, ainda que de produtos e materiais reciclados, não enfranto o problema do consumo de modo aprofundado. Tal situação também se verifica se analisada a seção referente aos incentivos para a implementação e efetividade da responsabilidade compartilhada, mais especificamente a partir do art. 42 da Lei. Nela, a grande arma parece ser o incentivo, através do princípio do protetor recebedor que, no art. 44, comporta a instituição de conceção de incentivos fiscais, financeiros ou creditícios para industrias de reciclagem, projetos e empresas destinadas à limpesa urbana. Os consumidores não aparecem como beneficiários de quaisquer estímulos oriundos do princípio do protetor recebedor. A mesma situação se repete no decreto 7.404/2010, regulamentador da PNRS, que se refere ao consumidor, mais detidamente, somente no que concerne à educação ambiental.

Portanto, a despeito dos avanços trazidos pela PNRS para buscar mitigar o problema dos resíduos no pais, especialmente as diretrizes direcionadas ao mercado produtivo, estimulando a reciclagem e a reutilização, bem como o transporte e descarte adequado, parece que a lei não atinge o âmago do problema, que está vinculado à lógica do consumo e da descartabilidade desenfreados. Isso porque, mesmo sendo mais ambientalmente saudável a utilização de produtos reciclados, muitos estudos apontam para um certo mito da reciclagem que, se de um lado diminui a exploração dos recursos naturais, por outro gera uma série de problemas em muitos dos procesos de reciclagem. 
Um novo mercado estimulado, ainda que de produtos "verdes", não parece ser a solução para a questão dos resíduos sólidos no país.

\section{A FIGURA DO CONSUMIDOR-GERADOR E A CULTURA DA DESCARTABILIDADE: OBSTÁCULOS PARA EFETIVAÇÃO DA LEI 12.305/2010.}

Privilegiando uma análise que não considere o lixo de forma desconectada da realidade histórica, política, econômica e cultural, não há como descuidar da figura do consumidor-gerador, ou seja, aquele que é tido, como o destinatário final dos bens e serviços. O próprio Código de Defesa do Consumidor, em seu art. $2^{\circ}$, assim o define ${ }^{8}$. $\mathrm{Na}$ verdade, verifica-se uma tecnologia jurídica recente na proteção do consumidor, especialmente porque ele se constitui a mola mestra de toda a economia de mercado. A proteção do consumidor, que não se questiona quanto a seus méritos, é, de outro modo, uma forma de estimular o consumo de modo a permitir a mobilidade permanente de produtos circulando na economia, sejam esses produtos reciclados, recicláveis, ou não.

Neste sentido, enfrentar a questão dos resíduos sólidos importaria em enfrentar mais diretamente a estimulação do consumo, o que importa questionar a própria estrutura social e cultural implantada. Sobre esse ponto Maurício Waldman (2010) refere que a cultura organizacional da modernidade determina uma noção de tempo cada vez mais veloz, onde os produtos devem ser consumidos e descartados para a reposição constante dos bens. Refere o autor ainda que

\footnotetext{
No seu entrosamento mais literal, validar o dinamismo do mercado implica em promover descarte contínuo dos bens, ejetados do carrossel do consumo. Na perspicaz argumentação devida ao filósofo Abraham Moles, vivemos numa civilização consumidora que produz para consumir e cria para produzir, um ciclo onde a noção fundamental é a de aceleração (WALDMAN, 2010, p. 123)
}

O próprio sistema de mercado, portanto, para a sua manutenção, deve estimular cada vez mais o consumo de bens, mesmo que estes sejam considerados inúteis. $\mathrm{Na}$ verdade, segundo o autor, quanto antes e quanto mais os produtos se tornarem inúteis,

\footnotetext{
${ }^{8}$ Lei $\mathrm{n}^{\mathrm{o}} 8.078 / 90$, em seu art $2^{\circ}$ considera consumidor é toda pessoa física ou jurídica que adquire ou utiliza produtos ou serviço como destinatário final
} 
III SEMINÁRII ECOLOGIA

PDLÍTICA

E DIREITO NA AMÉRICA LATINA

diante dos conceitos imiscuídos aos objetos, entronizados como meta principal das compras. Difunde-se uma desutilidade qualitativa, que, legitimada pela parafernália midiática e pelo lazer teledirigido, substituiu progressivamente a qualidade de vida enquanto parâmetro de bem-estar (WALDMAN, 2010, p. 126-127)

Hannah Arendt (2001), na obra a condição humana, ao analisar a questão do homo faber, já direcionava sua crítica a uma sociedade individualista do consumo gerada para a manutenção de um sistema perverso, que desconsidera o valor intrínseco das coisas e volta-se para a satisfação dos objetivos individuais. A partir de uma leitura desta autora, Patrícia Lemos (2011, p. 31), refere que o consumo deixa de corresponder às necessidades vitais, relacionando-se, cada vez mais, com coisas supérfluas.

Portanto, verifica-se que existem uma série de entraves, profundos e enraizados no imaginário social, para a efetiva redução da produção de resíduos, especialmente para a redução do consumo. Neste sentido, embora meritoza a PNRS, a sua efetividade mostra-se ameaçada por não enfrentar as questões que dizem respeito diretamente ao consumidor-gerador. Este, talvez um dos grandes responsáveis pela produção dos Resíduos Sólidos Domésticos, e que, pelas pesquisas apresentadas, tendem a aprofundar-se na produção cada vez maior de resíduos.

Uma Política de Resíduos Sólidos portanto, vista sob um ponto de vista sistêmico, deveria enfrentar o marketing desenfreado e a produção de desejos realizados pelas mídias contemporâneas cotidianamente, teleguiando os indivíduos no sentido de consumirem cada vez mais e, ato-contínuo, descartarem cada vez mais produtos. Além disso, a perversidade desse sistema atinge, especialmente, as crianças, bombardeadas diariamente com estímulos ao consumo e ao descartável. Estas questões, portanto, apresentam-se como verdadeiros entraves para a melhoria ambiental e, de fato, para a construção de uma sociedade efetiva e ambientalmente sustentável.

\section{CONSIDERAÇÕES FINAIS}

Da pesquisa, ainda que panorâmica, dos exemplos analisados, pode-se verificar que o problema dos resíduos, especialmente os resíduos sólidos domésticos, são de enorme complexidade, envolvendo uma série de fatores que fogem à análise ideal ou 
puramente normativa, especialmente por estarem diretamente relacionadas à estrutura da sociedade de consumo e ao próprio âmago do sistema de economia de mercado.

Nos moldes como o sistema é estruturado, verifica-se um incentivo cada vez maior ao consumo e à descartabilidade de bens, como forma de manutenção da própria sociedade capitalista, modelando os comportamentos através de recursos midiáticos e de uma indústria cultural que se aloja no inconsciente coletivo, determinando um verdadeiro habitus voltado para a satisfação individual através do consumo de bens e serviços, erigidos à condição de verdadeira religião.

Muito embora a Lei $\mathrm{n}^{\circ} 12.305 / 2010$ tenha trazido significativos avanços na questão do tratamento de resíduos sólidos, especialmente por seus instrumentos e responsabilidade compartilhada, logistica reversa, análise sistêmica das questões relacionadas a geração e a gestão de resíduos, verifica-se que não enfrentou as questões relacionadas ao consumidor-gerador, especificamente no que se refere ao estímulo permanente e constante ao consumo. Pelo contrário, a PNRS, em certos momentos, parece direcionar-se apenas para a substituição da forma como se apresenta o consumo, e não no efetiva reflexão sobre o ato de consumir. Em certos aspectos a lei volta-se jutamente para o estímulo ao desenvolvimento do mercado, a produção e o consumo, ainda que de materiais reciclados ou recicláveis.

Por estes motivos, é possível imaginar uma eficácia relativa da Política Nacional de Resíduos Sólidos, na medida que encontra barreiras na própria estrutura do sistema capitalista, voltado para a produção, consumo e descartabilidade de produtos de maneira cada vez mais veloz e crescente. Em que pesem os avanços, a solução legislativa parece padecer de problemas congênitos, a demonstrar que ainda são grandes os desafios para a construção de um consumo efetiva e ambientalmente sustentável, bem como de um tratamento e gestão de resíduos que, de fato, atinjam aos objetivos propostos pela própria Lei no $12.305 / 2010$.

\section{REFERÊNCIAS BIBLIOGRÁFICAS}

ABRELPE - Associação Brasileira de Empresas de Limpeza Urbana e Resíduos Especiais. Panorama dos Resíduos Sólidos no Brasil 2009 disponível, em http://www.wtert.com.br/home2010/arquivo/noticias_eventos/Panorama2009.pdf $>$, acesso em 15.08.2012. 
